\title{
Widening of the M4 motorway between Tredegar Park and Malpas: design, traffic management and construction
}

\author{
J. G. EVANS. T. M. BRAITHWAITE \& \\ D. A. GOLDSMITH
}

\section{Mr Evans, Mr Braithwaite and Mr Goldsmith}

Chapter 8 of the Traffic signs manual ${ }^{1}$ has been used for several years to provide a uniform standard of safety for road works. Since its introduction there has been a considerable increase in the number of motorway widening and reconstruction schemes. The traffic management of these schemes has tended to vary, particularly in terms of the signing and layout of cones, cylinders, lane markings etc., even though it has generally been based on the above document. It is felt that this variance is probably the result of the standards adopted by the appropriate authority rather than a factor of the traffic patterns or carriageway geometry.

48. It seems appropriate therefore to reconsider the requirements of the Traffic signs manual in the light of the experience gained on the traffic management of motorway schemes in order to adopt a uniform approach throughout the UK. It is suggested that new standards be adopted to take account of such factors as highway geometry, interchanges, signing and lighting. The latter aspect is of some importance, as physical and safety considerations often cause conflict with the stated lighting requirements of The traffic signs regulations and general directions. ${ }^{2}$

49. The project under discussion has emphasized that close and regular liaison is essential between all directly affected parties (particularly the police and highway authority) in order to minimize possible problems in both the short and long term. Views from these bodies should also be taken into account in adopting any new standards.

50. The project also demonstrated the success of night work (in the tunnels) and concentrated weekend work under limited closures. Hence in the design of any scheme one should consider the cost-benefit situation of such operations, but bear in mind the problems of roadworks material supplies and associated difficulties in maintaining good standards of workmanship under unusual working conditions.

Paper published: Proc. Instn Civ. Engrs, Part 1, 1981, 70, Aug., 501-518 


\section{Mr D. S. Wills, Sir Owen Williams and Partners}

The principles of contra-flow are fairly simple in concept, but the practical application of those principles can be very complex, and I think in the case of Newport this was particularly so. The close spacing of the junctions, and the proximity of the Crindau Tunnels to one of those junctions certainly created complications. Consequently the pre-planning had to be detailed and comprehensive.

52. In the original design for the bypass in the early 1960 s we were working to design capacity figures of 33000 p.c.u./day for a dual two-lane carriageway. The construction of the bypass was not finished until 1967, by which time the traffic figures were getting out of date. Within 10 years of the completion of construction the bypass was running at the equivalent of over 45000 p.c.u./day. Although carriageway design capacities were increased (particularly in the Department of Transport memorandum H6 74), it became clear that widening would be inevitable. When my firm was asked in 1976 to start the detailed design, the contra-flow system of traffic management was in its fairly early days. Some schemes in Staffordshire and Worcestershire gave some very useful information. The prime consideration was the need to maintain two lanes in each direction and to have a buffer lane between the working area and running traffic, preferably the width of a traffic lane. Taking those factors into account, there was only one way it could be done. We had to eliminate single-lane working, and contra-flow was the only answer.

53. We were helped by the fact that the hard shoulder was of full construction and full depth. I note in recent Department of Transport memoranda that the hard shoulder is required to be of the same strength as the main carriageway. I think that is a very good move.

54. One of the other constraints we had in the design was to maintain the existing boundaries, and it was essential that we did not acquire additional land for the widening. This meant that we had to put retaining walls on one of the sections up through the Bassaleg Cutting to Risca Road. For the design of those walls we looked at a range of possibilities, including in situ reinforced concrete, precast concrete and continuous piled walling. Eventually we decided that the simplest and most flexible method was a mass concrete wall with precast facing blocks. The design is based on the line of thrust passing through the centre of the base at or near right angles to the under side of the foundation, which has a back slope of about $20 \%$. The back slope of the foundation greatly adds to its stability in sliding. I appreciate that it is more difficult to form a sloping foundation; the greatly improved stability is the principal reason for doing it.

55. The present cost of the section of widening between Tredegar Park and Malpas is of the order of $\mathrm{f}^{\frac{1}{2}}$ million per kilometre. This would represent less than $£ 100000$ per kilometre in 1967 when the bypass was completed. That represents roughly what the cost would have been if the additional width had been constructed in the original contract. In discounted investment terms, therefore, the deferment of the capital expenditure has not been disadvantageous, particularly as the motorway now has a new lease of life, with consequent savings in maintenance.

56. I have no doubt that the success of the project was largely due to the collaboration at the traffic management meetings which were held regularly throughout the contract between all concerned; it was accepted that there would be no change in the pre-planning unless the management meeting had agreed the variation in detail. 
Mr G. Stapleton, Hereford and Worcester County Council

In contra-flow traffic systems on M5 in Hereford and Worcester cone and bollard loss can exceed 100 per night. Tapers of traffic cones are regularly demolished; the present one on M5 has been demolished on three consecutive nights, including lamp columns and safety barrier. It has been found that walls of cones help to reduce losses, presumably because they present a more positive demarcation.

58. With reference to $\S 12$, I wonder who was responsible for maintaining the open carriageway. In recent motorway contracts the responsibility for signing and coning and maintaining the open carriageway has been transferred to the contractor. The live carriageway therefore becomes part of the work site and my own view is that this is not a sensible arrangement. Maintenance of the live carriageway is far more sensibly carried out by the agent authority.

59. I would like to ask if the original tender included for working at night. There seems to be a mental block about night working on motorways which I cannot understand. Miners, nurses and many other people work at night, but night-time road works are resisted. This is understandable because of the inherent difficulties, but on a densely trafficked motorway it can be easier and safer working at night, and where densities are extreme it may be the only solution.

60. Cost is obviously a big factor and if night works are going to be undertaken seriously for lengthy periods adequate shifting of resources is essential. Working hours are often increased by unreasonable extension of the normal working hours, using the same people. Extensive use of this method causes fatigue and introduces unwarranted risk. If proper shift systems are established it should be more productive.

61. The Paper implies that rates for night-time working were being negotiated as the work progressed, with continuous shift working operating if required. It would be interesting to know how the items of work were billed and how a contractor could price items so as to allow for such an event.

62. In my experience where night work has been specified environmental problems have occurred; people do not like heavy lorries travelling through quiet villages and the noise of excavators during the night. Was any difficulty experienced in this respect? The imposition of a $50 \mathrm{mile} / \mathrm{h}$ mandatory speed limit is interesting. I am not aware that a mandatory restriction has ever been tried on temporary motorway works in England. I wonder how it was enforced. It is rather difficult stopping speeding drivers in a contra-flow situation.

63. The Authors say (\$32) that there was no evidence of accidents at emergency crossings and I think the authority should be congratulated on that achievement. I know of only one case where the accident rate was reduced on motorway works involving contra-flow; this was on the Midland Links Motorway Reconstruction Contract at Bescott. In most cases the accident rate increases by a factor of 3-4. I wondered if there was any specific reason why the accident rate did not increase. Was it the increased skid-resistance at the approaches to crossings, the mandatory speed limit, or any other particular feature?

\section{Mr B. D. Saunders. Howard Humphreys \& Partners}

In the construction of the new carriageway at the sides of the old carriageway, I would like to know if there were any problems on the site in finding a suitable formation, and what special measures were taken to ensure that the new work bonded with the old work. 
65. On the M1 motorway certain reconstruction works are in progress because the carriageway, as I understand it, has come to the end of its design life, in terms of millions of axle loads. I wish to know from what aspect this was considered during the design stage. I note with interest that the old hard shoulder was wisely built to the standard of the old carriageway, and I would ask what was taken into account where the old carriageway or hard shoulder had to be reconstructed or even widened to new crossfalls. What design life was envisaged, bearing in mind that the old carriageway carried about 33000 p.c.u.s when the bypass was opened and is now taking about 34000 p.c.u.s. How are the new slow lanes, because they are on the old hard shoulder or reconstructed, expected to stand up to this loading and what design life is expected?

66. What effect, if any, did the increase in impervious area due to the additional width of the carriageways have on the existing drainage systems, and was it necessary to enlarge the drainage systems of the outfalls?

67. I wish to know whether any modifications had to be made to structures at the Malpas Interchange.

\section{Mr Wills}

On the question of the pavement design life, it is true that the hard shoulder was to the same standard as the original pavement and therefore was sufficient to take the running traffic during the operation of the contra-flow system. The saving grace as far as design axle loading was concerned was the fact that a large part of the work was overlaid with an additional asphalt carpet, and this additional layer adds tremendously to the axle life. I think the design figure for the pavement life is in excess of 60 million; this should be adequate for the foreseeable future.

69. As regards modification of structures, two of the underbridges had to be widened but they were slab bridges and did not really present a problem. The overbridges remained as they were, which meant that the hard shoulder had to be curtailed at the overbridges. I am pleased to note that current Department of Transport memoranda require that on new motorways where there is a possibility of future widening the overbridges must suit the future widening.

Mr R. W. Bird, Sir Owen Williams and Partners

With reference to Mr Saunders' question on the drainage, a lot of the gradients were $4 \%$ and the pipes generally were 9 in in diameter, so there was a lot of spare capacity due to the high velocities in the pipe system. Moreover, in the original design an extra $10 \%$ was allowed on flow characteristics to allow for irregularities in pipe-laying, so there was generally ample spare capacity. One or two sections were under capacity and they were re-laid as part of the contract.

71. I found it a shattering experience to spend 4-5 h walking along the hard shoulder, with the traffic coming down those $4 \%$ grades at $70 \mathrm{mile} / \mathrm{h}$ or more, and the noise of the traffic passing. I would like to ask whether there was any increase in ear problems or complaints from the contractors' staff, or whether any special precautions were taken against noise for people working there.

The Chairman, Mr J. V. Bartlett

Do the Authors have any measure of the increase in the traffic capacity in the tunne's which resulted from the measures that were taken? Was there any special reas I for putting anti-skid surfacing into the tunnels, and what was used, please? 
Mr A. W. Shilston, Consulting Engineer

Concerning the high level of collaboration achieved between the organizations involved in this project, it would be helpful if further explanation could be given on how the meshing operated in practice.

74. Firstly, could the role of the Welsh Office in the promotion of highway schemes be described? The Welsh Office is a separate department of state. In England the promotion of highway schemes is the responsibility of a separate department of state, that of transport, with Cabinet ministerial representation. How does the Welsh Office mesh with the Department of Transport in matters of highway scheme promotion and the observance of technical design standards (which, in respect of England, have to conform with the all-pervasive edicts of the Department of Transport)?

75. The evolution of the design was the outcome of, and clearly called for, joint participation between consulting engineer and road manager. Did that involve joint responsibility for design formulation and contract preparation? As to the road scheme promoter's administration of the resulting construction contract, who was the Engineer and how wide was his remit?

76. The supposition is that the role of the police, in original design formulation, is purely advisory or consultative, but in matters of control of the activities of public road users and law enforcement over the developing new public highway, absolute. Is that correct?

77. Detailed procedures of traffic management during construction were written into the construction contract. Since traffic management activities permeate the economy of productive performance of the permanent works, what is the most efficacious way of providing within the scope of competitive tenders an appropriate allowance for what must be a difficult activity to price?

\section{Mr Evans, Mr Braithwaite and Mr Goldsmith}

Mr Stapleton's comments are of interest as he has had considerable experience of roadworks on the M5 motorway and obviously appreciates the problem associated with the maintenance of the traffic management.

79. At all times maintenance of the running lanes was the responsibility of the highway authority but the contractor was responsible for signing and coning. In any phase the contractor was required to carry out work on a particular carriageway which contained one lane of traffic. The latter had to be adjusted during the course of the works, particularly in surfacing operations, and thus the physical location of the site varied from day to day. On both contracts an excellent understanding was set up between highway authority and contractor-this co-operation enabled both parties to operate within the other's coned-off or working area, and minimized restrictions to traffic; on one occasion 17 different organizations were able to work over a $1500 \mathrm{~m}$ length of carriageway in a co-ordinated weekend operation.

80. Prior to the tender period it had been expected that the contract could start on such date that the tunnel works could be executed outside the peak summer holiday traffic flows. External factors gave a later start date than anticipated and put the programme out of sequence. Following unpredictable traffic behaviour, some night work was carried out adjacent to the tunnels and proved successful in terms of traffic management. The contractor was then asked to submit new rates for the tunnel works to be carried out during overnight occupations only. (Because 
of the heavy concentration of work in the tunnels the original contract envisaged that some shift work would be required.) The new rates provided reasonable comparison with savings on delay costs and were agreed prior to the commencement of the tunnel works, and the appropriate variation was made to the contract. The variation was extremely successful in traffic management terms but the contractor experienced some operating difficulties with subcontractors who were unaccustomed to regular night work. To some extent the latter was understandable as the nature of the tunnel works meant that it was not possible to set up a long term continuous shift for any subcontractor.

81. A night trial run was carried out on setting up and removing the traffic management equipment for the tunnel closures, before the main work started, and advantage was taken of this to monitor noise levels with typical operating plant. These indicated that noise levels emanating from traffic were only marginally increased by the tunnel works. The only complaints regarding noise followed one overnight planing operation on the motorway. General experience on the motorway indicated that the public complained about intermittent noise from generators and pumps rather than louder continual noise.

82. All those involved on the widening projects were extremely pleased with the accident record and it was felt that the experience gained on other works had proved beneficial. Vehicle speeds were to some extent dictated by traffic flows and motorway alignment, but the mandatory speed limit was probably the greatest single influence on the accident statistics. Accidents are obviously reduced when drivers are given more tolerance for error or an increased reaction time and any factors which improve these items should be incorporated in similar schemes. On the M4 schemes such factors were lower vehicle speeds, provision of the double row of cylinders between opposing flows of traffic, and the combination of skidresistant surfacing and the additional safety area provided by the splitter island at emergency crossings.

83. The situation with regard to the construction problems raised by $\mathbf{M r}$ Saunders was that most of the material encountered was hard marl which produced high values of CBR at both cuttings and embankments. Some slight problems were encountered where the embankment verges had become softened, probably by trapped rainfall, and small quantities of unsuitable material had to be removed below formation level. A similar situation also occurred locally where one carriageway was lowered in a cutting-no deformation was noted on the original carriageway but there was evidence of softening immediately below formation level.

84. In view of the strength of the subgrade it was felt that special measures were not required in joining new and existing construction. The latter comprised sub-base, lean concrete lower base, flexible upper base, base course and wearing course. The normal method of stepped laps between the different layers was adopted except where it was not found possible to separate the original asphalt base and wearing courses. New wearing course was laid over all three lanes and hard shoulder of each carriageway.

85. In reply to $\mathrm{Mr}$ Bird, no complaints were received on noise from anyone working on the motorway and it may be that all concerned were used to working on highway schemes where most plant tends to generate a considerable amount of noise. It tended to be rather disconcerting initially standing in the central reserve during phase 1 works with traffic flowing in both directions only a few metres away. One had to be extremely aware of the situation and it is a tribute to the 
contractor's planning that no one suffered serious injuries on site nor were there any incidents between site and highway traffic.

86. With regard to the Chairman's points the flow of traffic has not been measured in the tunnels since the associated works were complete. It would be a difficult situation to cover in view of the effect of the interchanges adjacent to either side of the tunnel, and current proximity of the traffic management for the second widening project. As part of the tunnel works sets of detector loops were buried under the carriageways to give the police immediate warning of any excessive decrease in vehicle speeds through the tunnel. A study has recently been undertaken to assess the possibility of using these loops for traffic counts.

87. Skid-resistant surfacing comprised the Shellgrip system produced by Colas (UK) Ltd, its purpose being two-fold: firstly, to increase the skid-resistance of the surfacing and hence increase the safety aspect in the tunnels, and secondly, to extend the life of the existing surfacing which, with the exception of one or two areas requiring local patching repairs, was generally in a good sound condition.

88. Some of the points raised by Mr Shilston have been touched on in the Paper and discussion but require further definition to clarify the situation.

89. The basic contract administration was between the employer (The Secretary of State for Wales) and the contractor (Reed and Mallik Ltd). The Engineer was Sir Owen Williams and Partners. Day-to-day running of the site was in the hands of the Contractor's Agent and Sir Owen Williams and Partners' Resident Engineer - this system sufficed for the major part of each phase where the traffic management arrangements tended to be static. Prior to any changes in traffic alignment, lane closures or diversions proposed by the contractor, the Resident Engineer discussed the matters fully with representatives of the employer, highway authority and police. These discussions usually took the form of site traffic management meetings, which were attended by the contractor-similar meetings also took place at 2-4 week intervals - with the highway authority and police being represented by their traffic management sections, who carried out any necessary liaison within their own organizations. Regular informal contact (almost on a day-to-day basis) was made between the Resident Engineer and the above parties when public complaints were received or it was felt that highway safety could be improved. In general two lanes were kept open in each direction except where lane or carriageway closures were necessary for certain operations. Such closures were not permitted during weekday peak periods, Bank Holidays, summer holiday periods or other times when local factors could produce traffic congestion.

90. The project was promoted by the Welsh Office-Transport and Highways Group-acting on behalf of the Secretary of State for Wales. General design standards in England and Wales are co-ordinated but are not necessarily identical.

91. The total design of the scheme was the responsibility of Sir Owen Williams and Partners but within the brief of the Welsh Office. This design was based on experience within the firm but took account of similar works executed elsewhere. Prior to the tender stage discussions were also held with the Welsh Office, Gwent County Council and Gwent Constabulary, and their specialized local knowledge and requirements were built into the contract as far as conditions permitted. The Engineer supervised the contract under the ICE conditions of contract.

92. As noted before, the police provided advice in drawing up the contract documents and were responsible for all aspects of law enforcement for traffic on the running lanes. They were advised prior to, and at the time of, any lane or 
carriageway closure and where necessary provided the appropriate traffic control during the operation of the closure. (Some 700 nightly closure and opening operations of the tunnels took place with the assistance of a police control car without a single traffic incident.) Although the contractor was permitted to execute closures within the contract and under the supervision of the Resident Engineer, no such operation took place when the advice of the police indicated that a traffic hazard might result or the safety of the men carrying out the operation would be imperilled; such situations tended to arise in adverse weather conditions.

93. Traffic management, on the scale of schemes now being carried out, is a fairly specialized subject and in view of the fact that it can be equivalent to $10-15 \%$ of the contract value it can be a vital factor in winning competitive tenders and the subsequent profitability of a contract. Like all aspects of estimating it is largely based on experience. (Although the latter is limited it is interesting to note the recent growth in companies specializing in such work.) In order to provide competitive tenders it is necessary for the client to set out his specific requirements for the general programme of works and phases for traffic management. The latter should include such details as spacing, location and type of cylinders or cones, signs, lighting, road studs, road markings and site accesses/exits. It will also be necessary to indicate any peculiar restrictions with respect to the timing of operations. From all this information the contractor should be able to set out his optimum main programme for the works, with the traffic management being carried out by the main contractor or his appointed subcontractors.

\section{References}

1. DePartment of the Environment. Traffic signs manual. Her Majesty's Stationery Office, London.

2. The traffic signs regulations and general directions 1975. Her Majesty's Stationery Office, London, 1975. Statutory Instrument 1975 No. 1536. 